\title{
Análise da Função Autonômica Cardíaca em Hamsters Chagásicos
}

\author{
Valdo José Dias da Silva, Marcus Paulo Ribeiro Machado, Aletheia Moraes Rocha, \\ Rone Marques Padilha e Luiz Eduardo Ramirez
}

A destruição de neurônios do sistema nervoso autônomo tem sido há muito descrita em pacientes chagásicos ${ }^{4}$. Esta desnervação autonômica parece exercer um papel preponderante na patogênese da forma digestiva da doença, uma vez que a destruição dos plexos mioentéricos do esôfago e do cólon alteram o funcionamento normal da musculatura lisa destas vísceras, levando ao desenvolvimento dos megas ${ }^{4}$. Enquanto o papel da desnervação autonômica digestiva na patogênese dos megas parece não deixar dúvidas, o papel desta mesma desnervação autonômica na patogênese da cardiopatia ainda é alvo de grande discussã $0^{4}$.

Koberle ${ }^{4}$ propôs a teoria neurogênica para o desenvolvimento da cardiopatia chagásica crônica, no qual a destruição preferencial dos gânglios intra-cardíacos vagais, por contigüidade anatômica com o tecido miocárdico inflamado na fase aguda, levaria a uma disfunção vagal crônica com prevalência a longo prazo do sistema nervoso simpático, reconhecidamente deletério ao coração. Entretanto, vários achados, tais como, corações chagásicos com miocardiopatia e contagem neuronal normal, disfunção autonômica cardíaca importante sem cardiopatia e lesão simultânea do simpático, tem trazido inúmeras dúvidas sobre o papel da desnervação autonômica na gênese da cardiopatia chagásica. Apesar disso, desnervação e consequente disfunção autonômica provavelmente desempenham um papel importante na gênese dos fenômenos arrítmicos e talvez da morte súbita, muito prevalente em pacientes chagásicos ${ }^{2}$.

0 emprego de modelos experimentais animais, para o estudo da doença de Chagas, tem permitido a aquisição de um enorme corpo de conhecimento sobre a patogênese da doença e poderia ser de grande valor para responder a importantes questionamentos relativos ao sistema nervoso autônomo: Como se dá e em que fase de evolução da doença ocorre a desnervação e disfunção autonômica cardíaca? Quais divisões do sistema nervoso autônomo são preferencialmente acometidos, simpático ou parassimpático? Que estratégias terapêuticas poderiam ser adotadas para minimizar o impacto da disfunção autonômica cardíaca?

Desnervação autonômica cardíaca tem sido descrita em modelos experimentais da doença de Chagas no cão, coelho, rato, camundongo e hamster. Porém, tem sido pouco investigado se a desnervação cardíaca descrita nestes modelos traz repercussões sobre a função autonômica cardíaca. Junqueira Jr. e cols. ${ }^{3}$ demonstraram em ratos cronicamente infectados uma atenuação da resposta vagal cardíaca à estimulação barorreflexa, a qual se correlacionou com a presença de neuroganglionite em gânglios intra-cardíacos ${ }^{3}$. Porém, as repercussões destes achados sobre a evolução da cardiopatia e sobre as alterações do ritmo cardíaco não foram investigados.
Nos últimos 20 anos, o emprego de métodos de análise de variabilidade de sinais cardiovasculares no domínio do tempo (métodos estatístico) e no domínio da frequiência (análise espectral) tem trazido grandes avanços no entendimento e na avaliação da função autonômica cardíaca em pacientes e animais experimentais. o emprego destas ferramentas de análise, pela primeira vez efetuado no modelo experimental da doença de Chagas em ratos, evidenciou uma marcada redução dos componentes espectrais de variabilidade de baixa ("low frequency" - LF) e alta frequiência ("high frequency" - HF) do sinal de frequiência cardíaca (intervalo RR), os quais têm sido associados à modulação prevalentemente simpática e parassimpática cardíacas, respectivamente, durante a fase aguda (20 dias) da infecção em ratos ${ }^{1}$. Surpreendentemente, todas estas alterações autonômicas não mais foram verificadas em ratos chagásicos na fase crônica da doença (180 dias), sugerindo uma completa recuperação do sistema nervoso autonômo neste modelo ${ }^{1}$. Assim sendo, o modelo de doença de Chagas crônico em ratos parece não simular muito bem o que ocorre na doença humana, onde a disfunção autonômica de grau variado é verificada em grande percentual dos doentes, independente da forma clínica ${ }^{4,6}$.

Em anos recentes, dados histopatológicos, imunológicos e parasitológicos têm indicado que o hamster inoculado pelo $T$. cruzi desenvolve uma cardiopatia com características parasitológicas e histopatológicas muito semelhantes à cardiopatia chagásica humana ${ }^{7}$. 0 estudo da função autonômica cardíaca em hamster, durante a fase aguda da doença de Chagas, demonstrou, à semelhança do rato, uma taquicardia persitente em condições basais, associada a uma depressão marcada na variabilidade total da frequiência cardíaca, bem como uma sensível diminuição do componente LF (modulação simpática) e HF (modulação parasimpática)(Figura 1)5. Nestes animais agudamente infectados, bloqueio autonômico com atropina e propranolol evidenciou um predomínio do sistema nervoso simpático, o que provavelmente está implicado na gênese da taquicardia ${ }^{5}$. Além disso, uma marcada atenuação do reflexo barorreceptor cardíaco foi observado. Todos os achados funcionais observados correlacionaram-se fortemente com os achados histopatológicos, principalmente uma miocardite multifocal moderada a severa 5 . Na fase aguda da doença, a disfunção autonômica também se amplia atingindo 0 território vascular periférico, como pode ser sugerido pela significativa redução associada do componente LF da variabilidade da pressão arterial'5 . Dados preliminares em hamsters cronicamente infectados também demonstram uma atenuação da variabilidade da frequiência cardíaca associada a uma 

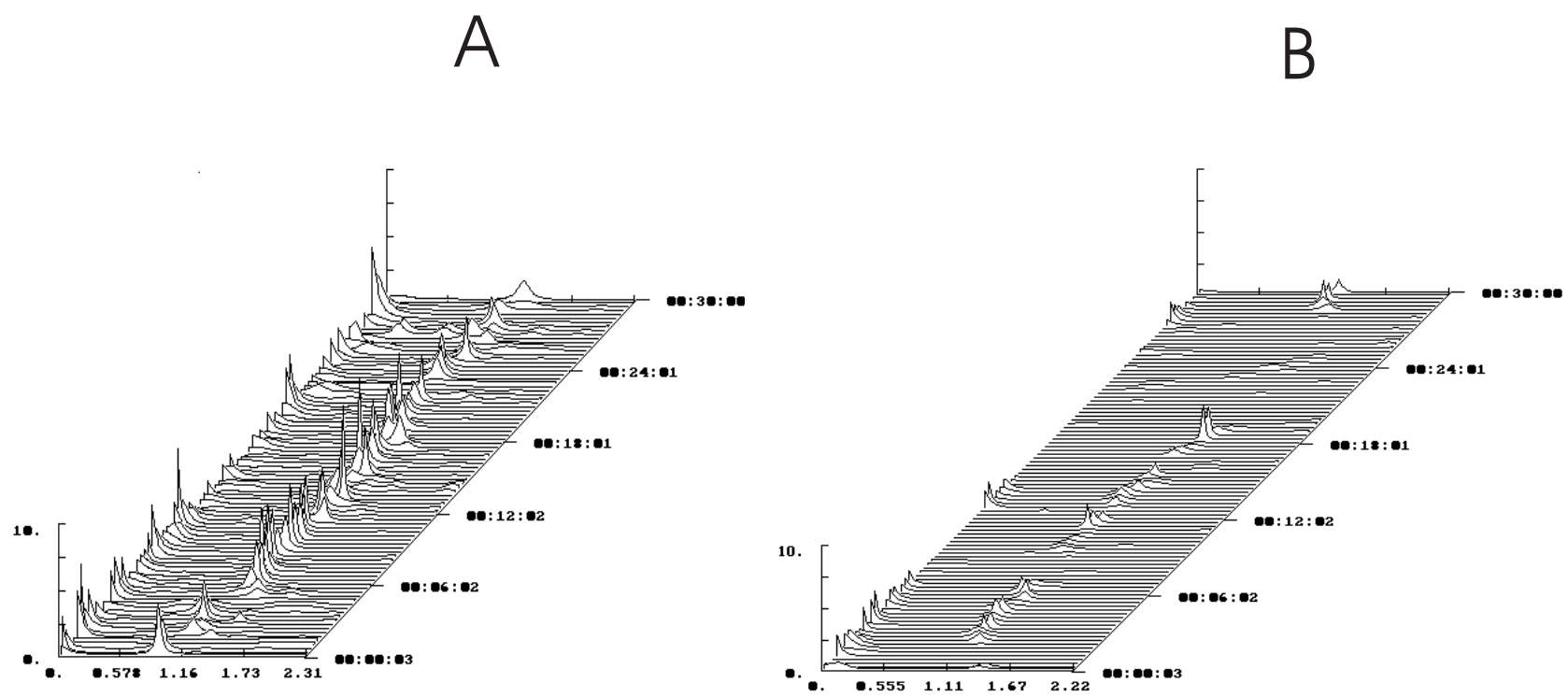

Figura 1 - Sequências espectrais da variabilidade do intervalo $R$ R representativas de um animal do grupo controle (painel A) e de um animal chagásico na fase aguda após 30 dias de infecção (painel B). Note a presença dos componentes espectrais de baixa (LF) e alta freqüência (HF) no hamster controle e a quase total ausência dos mesmos no hamster chagásico agudo.

redução menos marcante na sensibilidade barorreflexa, além de um quadro menos intenso de miocardite multifocal. Este resultados fazem do hamster um provável candidato de escolha para o estudo da disfunção autonômica cardíaca associada à doença de Chagas.

Em conclusão, o emprego do modelo experimental da doença de Chagas em hamsters tem permitido avanços consideráveis no entendimento da patogênese e das consequiências da disfunção autonômica cardíaca associada à doença de Chagas. Entretanto, estudos futuros sobre mecanismos moleculares e sobre o papel de diversas estratégias terapêuticas que minimizem os efeitos da disfunção autonômica cardíaca fazem-se ainda necessários.

\section{REFERÊNCIAS BIBLIOGRÁFICAS}

1. Dias da Silva VJ. Regulação Autonômica Cardiovascular na Doença de Chagas Experimental em Ratos. Tese de doutorado, Universidade de São Paulo, Ribeirão Preto, SP, 1998.
2. Junqueira Junior LF. Possible role of autonomic heart dysfunction in sudden death associated with Chagas disease. Arquivos Brasileiros de Cardiologia. 56:429-434, 1991

3. Junqueira Junior LF, Beraldo PS, Chapadeiro E, Jesus PC. Cardiac autonomic dysfunction and neuroganglionitis in a rat model of chronic Chagas' disease. Cardiovascular Research. 26:324-329, 1992.

4. Koberle F. Chagas' disease and Chagas' syndromes: the pathology of American trypanosomiasis. Advances in Parasitology. 6:63-116, 1968.

5. Padilha RM, Merino-Ruiz M, Cabrine MS, Lages-Silva E, Ramirez LE, Dias da Silva VJ. Cardiovascular Autonomic Modulation in Hamsters infected with Trypanossama cruzi: A Spectral Analysis Approach (abstract). Revista do Instituto de Medicina Tropical de São Paulo, 44: 53 - 53, 2002.

6. Prata A. Clinical and epidemiological aspects of Chagas disease. Lancet Infectous Disease. 1: 92-100, 2001.

7. Ramirez LE, Lages-Silva E, Soares Junior JM, Chapadeiro E. The hamster (Mesocricetus auratus) as experimental model in Chagas' disease: parasitological and histopathological studies in acute and chronic phases of Trypanosoma cruzi infection. Revista da Sociedade Brasileira de Medicina Tropical. 27:163-169, 1994. 